\title{
A Multilevel Analysis of Regressors of Access to Improved Drinking Water and Sanitation Facilities in Ghana
}

\author{
Pascal Agbadi $\mathbb{D}^{1}{ }^{1}$ Ernest Darkwah, ${ }^{2}$ and Paul L. Kenney ${ }^{3}$ \\ ${ }^{1}$ Department of Nursing, Faculty of Allied Health Sciences, College of Health Sciences, \\ Kwame Nkrumah University of Science and Technology, Kumasi, Ghana \\ ${ }^{2}$ Department of Psychology, University of Ghana, P.O.Box LG 84, Legon, Ghana \\ ${ }^{3}$ Institute of Statistical, Social and Economic Research, University of Ghana, P.O.Box LG74, Legon-Accra, Ghana \\ Correspondence should be addressed to Pascal Agbadi; pascalagbadi@gmail.com
}

Received 5 December 2018; Revised 18 April 2019; Accepted 5 May 2019; Published 4 June 2019

Academic Editor: Jonathan Haughton

Copyright () 2019 Pascal Agbadi et al. This is an open access article distributed under the Creative Commons Attribution License, which permits unrestricted use, distribution, and reproduction in any medium, provided the original work is properly cited.

\begin{abstract}
People's access to quality water and sanitation resources significantly improves their health. Using the 2014 Ghana DHS dataset, multilevel robust Poisson regression modelling was performed to investigate the factors that enhance Ghanaian households' access to improved sources of drinking water and toilet facilities. The results indicated that household head and household socioeconomic factors have significant effects on access to improved sources of drinking water and toilet facilities, and this varies from one community of residence to another. The following households had a higher probability of having access to improved sources of drinking water: female-headed households, households with heads who had at least attained middle-school-level education, urban households, and nonpoorest households. Correspondingly, the following households were more likely to have access to improved toilet facilities: female-headed households had a higher chance of access, as well as those whose heads had at least middle-school-level education, were at least 35 years old, or were currently married, rural households, households with a minimum of seven members, and households who attained at least middle wealth status. In their efforts to increase citizens' access to improved water and sanitation facilities, the government and other development organizations should develop citizens' wealthcreation capacities and enable their attainment of formal education.
\end{abstract}

\section{Introduction}

Safe water and sanitation are prerequisites of health, human growth, and development. Thus, promoting and ensuring people's access to improved sources of water and sanitation facilities are both public health promotion and human right agenda $[1,2]$. Unhygienic sources of drinking water and unhealthy sanitation facilities result in skin diseases, acute respiratory infections (ARIs), diarrheal diseases, Guinea worm disease, typhoid, cholera, schistosomiasis, trachoma, dysentery, death, etc. [3-6].

In 2015, unsafe water, sanitation, and hygiene (unWASH) practices resulted in about 1,766,000 global deaths and about 95,305,000 global disability-adjusted life years (DALYs) [7]. The same conditions resulted in about 7,300 deaths and 435,500 DALYs in Ghana in 2015 [7]. In Ghana, mortality and morbidity attributable to unWASH in children and adults are stabilizing, but unWASH practices remain common causes of death and morbidity in the country. In Ghana, about $87 \%$ of the population has access to safe drinking water, about $15 \%$ has access to improved toilet facilities, and about $20 \%$ practice open defecation [8].

Existing literature indicates that a plethora of social, economic, political, and environmental factors explain the differences in access to improved sources of drinking water and toilet facilities around the world. Studies have suggested that the region of residence, locality (urban/rural) of residence, household size, household wealth status, and the household head's characteristics (such as gender, age, level of education, marital status, and employment status) are significantly related to the household's access to improved water and sanitation facilities in places such as Zambia [9], Nigeria [10], Bhutan [11], Indonesia [6, 12, 13], Timor-Leste [14], Kenya [15], and Ethiopia [16]. 
Data on the prevalence of the debilitating effects of unWASH in Ghana are within reach, but only a few publications have investigated the socioeconomic structures that increase Ghanaian residents' access to quality water sources and sanitation infrastructures [17-19]. The only study that used nationally representative data (2008 DHS data) did not adopt a statistical approach that accounts for the hierarchical nature of the data. Ignoring clustering in analyzing data could result in underestimation of parameters [20]. Using the 2014 Ghana Demographic and Health Survey dataset, we performed a multilevel robust Poisson regression modelling in order to illuminate prevalence ratio which is preferred over the odds ratio for most cross-sectional studies [21-24]. Taking the community of residence as a level 2 unit, we sought to answer the following questions: (i) What factors predict access to improved sources of drinking water for Ghanaian households? (ii) What factors predict access to improved toilet facilities for Ghanaian households?

\section{Materials and Methods}

2.1. Design. The 2014 Ghana Demographic and Health Survey (GDHS) dataset used in this paper was collected in accordance with cross-sectional design protocols [8]. The 2014 GDHS was implemented by the Ghana Statistical Service (GSS), the Ghana Health Service (GHS), and the National Public Health Reference Laboratory (NPHRL) of the GHS [8]. The survey employed two-staged probability sampling in the ten administrative regions of Ghana [8].

The 2014 GDHS used an updated sampling frame from the 2010 Ghana Population and Housing Census acquired from the Ghana Statistical Service [8]. The first stage of the probability sampling involved the selection of enumeration areas (EAs) [8]. A total of 427 EAs were selected, 216 in urban areas and 211 in rural areas [8]. The second stage of the probability sampling involved the systematic sampling of households [8]. The implementers of the survey undertook a household-listing operation in all the selected EAs from January through March 2014, and households to be included in the survey were randomly selected from the list [8]. Approximately 30 households were selected from each EA to constitute a total sample size of 12,831 households [8].

2.2. Data Collection. Data collection was done by trained enumerators from early September to mid-December 2014 using paper-based questionnaires [8]. The selected sample size for the 2014 GDHS was 12,831 households, of which 12,010 were occupied [8]. Out of the occupied households, 11,835 were successfully interviewed, resulting in a response rate of 99 percent [8].

2.3. Study Area. The study area is Ghana. Ghana returned to multiparty democracy in 1992 and has since enjoyed relative political stability and peace. Ghana's population is about 29 million. Accra, in the Greater Accra Region, is the administrative and political capital city of Ghana. Ghana has embarked on many programs of industrialization, economic growth and development, education, health, and poverty alleviation that have attracted funding from international governments and multinational agencies. In the past three decades, many of these economic development programs have reached all the regions of Ghana through decentralization and local governance reforms. The country has made some significant economic gains by coming out of a highly indebted poor country (HIPC) status to its current lower-middle income. Ghana's national estimates of the adult literacy rate, poverty level, doctor-to-patient ratio are $56 \%, 24 \%$, and one doctor to 800 patients, respectively [25]. The relatively good national estimates, however, mask the prevailing socioeconomic inequalities between urban and rural areas and among the ten administrative regions in Ghana [25]. Regions in the north of Ghana are economically marginalized compared to the regions in the south. Also, economic disparities exist between rural and urban areas of the country. About 38\% of Ghanaians in rural areas are poor compared to about $11 \%$ urban poor [25]. The three regions-Upper West, Upper East, and Northern-in the north of Ghana are much poorer compared to the regions in the south. Out of $6,384,058$ poor people in Ghana, about $2,337,591$ (representing 37\%) are found in the three northern regions of Ghana [25]. The Greater Accra Region, with a poverty rate of 3.8 , has the least number of poor people in Ghana [25].

Rural-urban disparities in access to improved sources of drinking water have been reported. About $93 \%$ of the urban population have access to improved sources of drinking water compared to $84 \%$ rural dwellers [26]. In a report by Nana Yaw and Sarah [27], it is noted that about $20 \%$ of the entire country's population practice open defecation. The practice is much more prevalent in the three regions of Northern Ghana-Northern, Upper East, and Upper West-where more than $70 \%$ of the population practice open defecation [27]. The report further noted that almost $51 \%$ of Ghanaians use communal latrines which, according to the Joint Monitoring Programme of WHO/UNICEF, are classified as unimproved [27].

2.4. Study Sample. The unit of analysis is households, and the number of cases in the dataset was 11,835 households. Six cases had missing information in some of the variables and were excluded from the analysis; thus, there were 11,829 analytic samples. In the GDHS, household heads provided information on their demographic characteristics and household characteristics such as household population and composition, housing structure, household assets, access to basic utilities, sources of drinking water, water treatment practices, access to sanitation facilities, and type of fuel used for cooking [8].

2.5. Variables. The variables used in the study have been listed and described in Table 1.

2.6. Data Analysis. Statistical analyses were performed in R freeware version 3.5.3 [28] and SAS software version 9.4 [29]. Statistical significance was pegged at thresholds of $1 \%$ 
TABLE 1: Criterion and explanatory variables.

\begin{tabular}{l}
\hline Variables \\
$\begin{array}{l}\text { Criterion variables } \\
\text { Sources of drinking water }\end{array}$ \\
$\begin{array}{l}\text { (i) Improved: a household is said to have access to an improved drinking water source if it } \\
\text { has water piped into its dwelling, water piped to a yard/plot, a public tap/standpipe, a tube } \\
\text { well/borehole, a protected dug well, a protected spring, rainwater, bottled water, or sachet } \\
\text { water }\end{array}$ \\
(ii) Unimproved: a household is said to have access to an unimproved drinking water \\
source if it has an unprotected dug well, an unprotected spring, a tanker truck/cart with a \\
small tank, or surface water
\end{tabular}

Explanatory variables

Sex of the household head

Age of the household head

Education level of the household head

Marital status of the household head

Household wealth index

Household size

Place of residence of household

Region of residence of household

Primary sampling unit (i) Male (ii) Female

(i) 15-34 years (ii) 35-54 years (iii) 55 years and above

(i) No education/preschool (ii) Primary (iii) Middle/JSS/JHS (iv) Secondary/SSS/SHS (v) Postsecondary

(i) Never married/never lived together (ii) Currently married (iii) Formerly/ever married (i) Poorest (ii) Poor (iii) Middle (iv) Richer (v) Richest

(i) 1-3 (ii) 4-6 (iii) 7+

(i) Rural (ii) Urban

(i) Greater Accra (ii) Eastern (iii) Volta (iv) Central (v) Western (vi) Ashanti (vii) Brong Ahafo (viii) Northern (ix) Upper East (x) Upper West Handled as a community in the study and $5 \%(p \leq 0.01$ and $p \leq 0.05)$. The pastecs and gmodels packages in $\mathrm{R}$ were used to perform summary statistics and bivariate analyses, respectively. The lme4 package was used to model the multilevel binary models, and the sjstats packages were used to determine their intercluster correlation coefficients. The SAS PROC GENMOD with the specification of SUBJECT $=$ cluster identifier in the REPEATED statement was used to perform the two-level multilevel Poisson regression modelling by the use of the sandwich variance estimator [24]. Models that fit with the REPEATED statement use the generalized estimating equation (GEE) method to estimate the model. Thus, the quasi-likelihood information criterion (QIC), instead of the popular Akaike's information criterion (AIC), is used to evaluate the goodness of fit of the models because the GEE method is not a likelihood-based method [30]. SAS version 9.4 provides the QIC value along with results in the output. Basically, the model with the smallest QIC is the best fitting model.

2.7. Binary Outcome Multilevel Modelling. Due to the stratified nature of data in the 2014 GDHS, the households are nested into communities of residence. To account for the hierarchically clustered nature of the survey dataset, multilevel robust Poisson models were generated to avoid possible underestimation of parameters from a single-level model and the potential overestimation of effects from reporting odds ratios when the prevalence rate is above $10 \%$ $[20,21,24,31]$. The community of residence was chosen as the level 2 variable under which the households (level 1 variable) are nested. Two multilevel robust Poisson regression modellings were performed to assess the impact of household head factors and household socioeconomic factors on a household's access to an improved source of drinking water and improved toilet facilities.

Four models were tested in each of the cases (access to an improved source of drinking water and access to improved toilet facilities). Model 0 is the null model, which assessed the percentage variation in access to improved sources of drinking water and improved toilet facilities explained by the level 2 units (community of residence). Model 1 investigated the impact of demographic characteristics of household heads on the likelihood of having access to improved sources of drinking water and improved toilet facilities. Model 2 assessed the impact of household socioeconomic factors on the likelihood of having access to improved sources of drinking water and improved toilet facilities. Model 3 assessed the impact of household head factors and household socioeconomic factors on access to improved sources of drinking water and improved toilet facilities. The association between the criterion variables and the explanatory variables was measured in adjusted prevalence ratio (aPR) and its $95 \%$ confidence interval (CI).

Assumptions of collinearity were checked, and no violations were observed; all explanatory variables in the models have the values of generalized variance inflation factors (VIFs) less than 4 which is far less than the cutoff value of 10 in [32] (see Table 2). 
TABLe 2: Collinearity statistics of explanatory variables.

\begin{tabular}{|c|c|c|c|c|c|}
\hline \multirow{2}{*}{ Explanatory variables } & \multirow{2}{*}{ Df } & \multicolumn{2}{|c|}{ Improved water model } & \multicolumn{2}{|c|}{ Improved toilet model } \\
\hline & & GVIF & $\operatorname{GVIF}^{\left(1 /\left(2^{*} \mathrm{Df}\right)\right)}$ & GVIF & $\operatorname{GVIF}^{\left(1 /\left(2^{*} \mathrm{Df}\right)\right)}$ \\
\hline Sex of the HH & 1 & 1.56 & 1.25 & 1.49 & 1.22 \\
\hline Age of the $\mathrm{HH}$ & 2 & 1.49 & 1.10 & 1.61 & 1.13 \\
\hline Education level of the $\mathrm{HH}$ & 4 & 1.42 & 1.04 & 1.53 & 1.05 \\
\hline Marital status of the $\mathrm{HH}$ & 2 & 2.21 & 1.22 & 2.29 & 1.23 \\
\hline Place of residence & 1 & 1.06 & 1.03 & 1.49 & 1.22 \\
\hline Household size & 2 & 1.34 & 1.08 & 1.32 & 1.07 \\
\hline Household wealth & 2 & 1.30 & 1.03 & 1.98 & 1.09 \\
\hline Improved source of water & 1 & & & 1.09 & 1.04 \\
\hline An improved type of toilet & 1 & 1.03 & 1.02 & & \\
\hline
\end{tabular}

GVIF: generalized variance inflation factor; Df: degree of freedom.

2.8. How the Criterion Variables Were Handled in the Analyses? For the first research question, the criterion variable denotes access to improved sources of drinking water, which takes the value 0 or 1 for each household $(0=$ unimproved sources of drinking water; $1=$ improved sources of drinking water).

For the second research question, the criterion variable denotes access to improved toilet facilities, which takes the value 0 or 1 for each household ( $0=$ unimproved toilet facilities; 1 = improved toilet facilities).

2.9. Ethical Considerations. The 2014 GDHS protocol was reviewed and approved by the Ghana Health Service Ethical Review Committee and the Institutional Review Board of ICF International. Informed consent was also obtained from participants before they were interviewed [8]. The GDHS is publicly available upon a simple, registration-access request, so no further ethical clearance was sought.

\section{Results}

3.1. Sample Characteristics. A total of 1,415 households and 10,406 households have access to improved toilet facilities (12\%) and improved sources of drinking water (88\%), respectively. Most households are headed by males (68\%). Most respondents have attained at least the basic school level of education-middle/JSS/JHS (34\%). Most household heads were currently married (63\%). The remaining sample characteristics are reported in Table 3.

3.2. Test of Association between the Criterion Variables and the Explanatory Variables. The chi-square test of independence was performed to explore (i) the relationship between households' sources of drinking water (SDW) and categorical explanatory variables (Table 4) and (ii) the relationship between types of toilet facilities used by households and categorical explanatory variables (Table 5).

3.3. Correlates of Improved Sources of Drinking Water. The analyses revealed that there was a statistically significant relationship between a household source of drinking water (SDW) and all the categorical explanatory variables (Table 4). Only about 1,293 households (12.4\%) had access to both improved sources of drinking water and improved toilet facilities.

3.4. Correlates of Improved Toilet Facilities. Table 5 reports the results of the chi-square test of independence between the types of toilet facilities (TTF) used by households and categorical explanatory variables. The analyses revealed that there was a statistically significant relationship between TTF used by households and all the categorical explanatory variables (Table 5).

3.5. Regressors of Access to Improved Sources of Drinking Water. Table 6 presents the adjusted prevalence ratios (aPRs) and confidence intervals (CIs) of a multilevel robust Poisson regression model delineating the predictors of households' access to improved sources of drinking water (ISDW) in Ghana. The following households were more likely to have access to improved sources of drinking water in Ghana: households with female heads, households with heads who at least have a middle-school-level education, urban residence households, and households that were nonpoorest (Table 6, Model 3). The ICC value of 0.76 indicates that $76 \%$ of the total variation in the criterion variable is accounted for by the community the households are located. Thus, the remaining $24 \%$ variability is due to the variation within the households and other unknown factors.

Compared to male-headed households, female-headed households had a higher probability of access to improved sources of drinking water (aPR: 1.01; 95\% CI: 1.00-1.03). Compared to households with heads without formal education, households with heads who attained middle/JSS/ JHS-level education (aPR: 1.02; 95\% CI: 1.00-1.04) or secondary/SSS/SHS-level education (aPR: 1.02; 95\% CI: 1.00-1.04) or postsecondary-school-level education (aPR: 1.03; 95\% CI: 1.00-1.05) had a higher chance of having access to improved sources of drinking water. Compared to rural households, urban households had a higher probability of having access to the improved drinking water source by $10 \%$ (aPR: 1.10; 95\% CI: 1.04-1.15). Compared to poorest households' access to improved sources of drinking water, households with the following wealth indices have the following positive implications: poor households had a $6 \%$ higher probability (aPR: 1.06; 95\% CI: 1.02-1.10), middle households had a 16\% higher probability (aPR: 1.16; 95\% CI: 
TABle 3: Descriptive analysis of variables $(N=11,829)$.



Note. Due to rounding errors, percentages may not equal $100 \%$.

$1.10-1.21)$, richer households had an $18 \%$ higher probability (aPR: 1.18; 95\% CI: 1.12-1.23), and richest households had an $18 \%$ higher probability (aPR: 1.18 ; 95\% CI: $1.13-1.24$ ).

3.6. Regressors of Access to Improved Toilet Facilities. Table 7 presents the adjusted prevalence ratios (aPRs) and confidence intervals (CIs) of a multilevel robust Poisson
TABLE 4: Bivariate analyses of SDW and explanatory variables.

\begin{tabular}{|c|c|c|}
\hline & \multicolumn{2}{|c|}{ Source of drinking water (SDW) } \\
\hline & $\begin{array}{l}\text { Unimproved } \\
\text { SDW }\end{array}$ & $\begin{array}{l}\text { Improved } \\
\text { SDW }\end{array}$ \\
\hline $\begin{array}{l}\text { Types of toilet facilities } \\
\text { Unimproved toilet facilities } \\
\text { Improved toilet facilities } \\
p \leq 0.001 ; \chi^{2}=17.73^{*} ; \mathrm{df}=1\end{array}$ & $\begin{array}{r}1307(91.5 \%) \\
122(8.5 \%)\end{array}$ & $\begin{array}{l}9107(87.6 \%) \\
1293(12.4 \%)\end{array}$ \\
\hline $\begin{array}{l}\text { Sex of the household head } \\
\text { Female } \\
\text { Male } \\
p \leq 0.001 ; \chi^{2}=66.38^{*} ; \mathrm{df}=1\end{array}$ & $\begin{array}{c}327(22.9 \%) \\
1102(77.1 \%)\end{array}$ & $\begin{array}{l}3498(33.6 \%) \\
6902(66.4 \%)\end{array}$ \\
\hline $\begin{array}{l}\text { Age of the household head } \\
15-34 \text { years } \\
35-54 \text { years } \\
55 \text { years and above } \\
p \leq 0.001 ; \chi^{2}=22.53 ; \mathrm{df}=2\end{array}$ & $\begin{array}{l}379(26.5 \%) \\
594(41.6 \%) \\
456(31.9 \%)\end{array}$ & $\begin{array}{l}3312(31.8 \%) \\
4282(41.2 \%) \\
2806(27.0 \%)\end{array}$ \\
\hline Education level of the hous & cead & \\
\hline No education/preschool & $618(43.2 \%)$ & $2728(26.2 \%)$ \\
\hline Primary & $280(19.6 \%)$ & $1382(13.3 \%)$ \\
\hline Middle/JSS/JHS & $415(29.0 \%)$ & $3667(35.3 \%)$ \\
\hline Secondary/SSS/SHS & $85(5.9 \%)$ & $1426(13.7 \%)$ \\
\hline Postsecondary & $31(2.2 \%)$ & $1197(11.5 \%)$ \\
\hline
\end{tabular}

$p \leq 0.001 ; \chi^{2}=343.10 ; \mathrm{df}=4$

Marital status of the household head

Never married/never lived

together

$123(8.6 \%)$

$1633(15.7 \%)$

Currently married

$1017(71.2 \%)$

$6437(61.9 \%)$

Formerly/ever married

$289(20.2 \%) \quad 2330(22.4 \%)$

$p \leq 0.001 ; \chi^{2}=62.44 ; \mathrm{df}=2$

\begin{tabular}{lcc}
\hline Household size & & \\
$1-3$ members & $629(44.0 \%)$ & $5638(54.2 \%)$ \\
$4-6$ members & $513(35.9 \%)$ & $3566(34.3 \%)$ \\
7 members and above & $287(20.1 \%)$ & $1196(11.5 \%)$ \\
$p \leq 0.001 ; \chi^{2}=99.43 ; \mathrm{df}=2$ & & \\
\hline Household wealth index & & \\
Poorest & $655(45.8 \%)$ & $1853(17.8 \%)$ \\
Poor & $551(38.6 \%)$ & $1867(18.0 \%)$ \\
Middle & $175(12.2 \%)$ & $2402(23.1 \%)$ \\
Richer & $42(2.9 \%)$ & $2243(21.6 \%)$ \\
Richest & $6(0.4 \%)$ & $2035(19.6 \%)$ \\
$p \leq 0.001 ; \chi^{2}=1286.00 ; \mathrm{df}=4$ & & \\
\hline Place of residence & & \\
Rural & $1192(83.4 \%)$ & $4702(45.2 \%)$ \\
Urban & $237(16.6 \%)$ & $5698(54.8 \%)$ \\
$p \leq 0.001 ; \chi^{2}=731.95^{*} ; \mathrm{df}=1$ & & \\
\hline Region of residence & & \\
Northern & $251(17.6 \%)$ & $763(7.3 \%)$ \\
Central & $118(8.3 \%)$ & $1110(10.7 \%)$ \\
Greater Accra & $32(2.2 \%)$ & $1305(12.6 \%)$ \\
Volta & $195(13.6 \%)$ & $920(8.8 \%)$ \\
Eastern & $231(16.2 \%)$ & $1076(10.3 \%)$ \\
Ashanti & $97(6.8 \%)$ & $1213(11.7 \%)$ \\
Brong Ahafo & $169(11.8 \%)$ & $1156(11.1 \%)$ \\
Western & $195(13.6 \%)$ & $1107(10.6 \%)$ \\
Upper East & $97(6.8 \%)$ & $901(8.7 \%)$ \\
Upper West & $44(3.1 \%)$ & $849(8.2 \%)$ \\
$p \leq 0.001 ; \chi^{2}+433.80 ; \mathrm{df}=9$ &
\end{tabular}

$p \leq 0.001 ; \chi^{2}=433.80 ; \mathrm{df}=9$

Note. ${ }^{*}$ Yates' continuity correction. Column percentages are reported. 
TABle 5: Bivariate analyses of types of toilet facilities and explanatory variables.

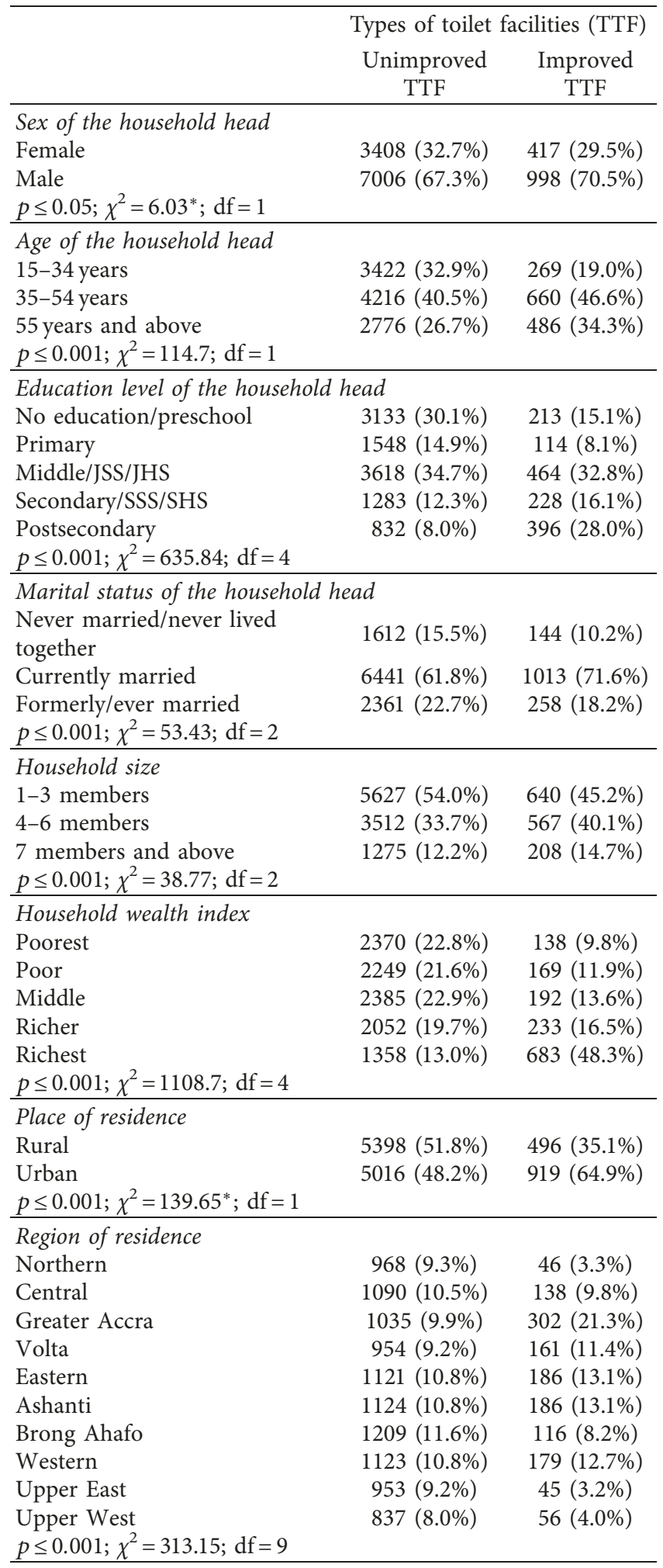

Note. *Yates' continuity correction. Column percentages are reported.

regression model outlining the predictors of households' access to improved toilet facilities (ITF) in Ghana. The following households were more likely to have access to improved toilet facilities: rural households, households with a minimum of seven members, and households who have at least middle wealth status (Table 7, Model 2). When household head factors were accounted for in Models 2 and 3 , it is clear that female-headed households, households with heads of at least 35 years old, and households with heads who attained at least a middle-school-level education increased the households' probability of having access to an improved type of toilet facility. The ICC value of 0.26 indicates that $26 \%$ of the total variation in the criterion variable is accounted for by the community the households are located. Thus, the remaining $74 \%$ variability is due to the variation within the households and other unknown factors.

In Model 2, compared to rural households, urban households had a lower probability of having access to improved toilet facilities by $38 \%$ (aPR: $0.62 ; 95 \%$ CI: $0.50-0.77)$. Compared to households with at least $7 \mathrm{mem}$ bers, households with 4-6 members (aPR: 0.77; 95\% CI: $0.65-0.85$ ) and households with 1-3 members (aPR: 0.48; 95\% CI: 0.42-0.55) had a lower likelihood of having access to improved toilet facilities. Compared to poorest households' access to improved toilet facilities, households with the following wealth indices have the following positive implications: middle households had an $81 \%$ higher likelihood (aPR: 1.81 ; 95\% CI: 1.37-2.34), richer households had a 219\% higher probability (aPR: 3.19; 95\% CI: 2.40-4.25), and richest households had an $844 \%$ higher probability (aPR: 9.44; 95\% CI: 7.08-12.61).

\section{Discussion}

This section discusses the results of the study presented above. The aim of the study was to investigate factors associated with access to improved sources of drinking water and toilet facilities in Ghana. We found that certain household head and household socioeconomic factors have significant effects on access to improved sources of drinking water and toilet facilities. However, the effects of such factors vary at the community level. This implies that the type of community a household is located in has an influence on its access to sanitation resources. We also observed a high prevalence in access to improved sources of drinking water. In all Ghanaian communities, public tap/standpipe, tube well/borehole, and purified sachet water, classified as improved sources of drinking water by the Joint Monitoring Programme of WHO/UNICEF, are within reach and are affordable. This suggests that general availability and provision of both quality water sources and toilet facilities will influence households' access.

The study again observed that the gender of the household head was a statistically significant predictor of the household's access to improved sources of drinking water and improved toilet facilities. More specifically, compared to male-headed households, female-headed households had a higher probability of having access to improved sources of drinking water and improved toilet facilities. One possible explanation for this result could be that relative to men, most sub-Saharan African women have a greater household responsibility (such as cooking, cleaning, and laundry) which 
TABLE 6: Predictors of access to improved sources of drinking water.

\begin{tabular}{|c|c|c|c|c|}
\hline Explanatory variables & Model 0 aPR (95\% CI) & Model 1 aPR (95\% CI) & Model 2 aPR (95\% CI) & Model 3 aPR (95\% CI) \\
\hline $\begin{array}{l}\text { Sex of the household head } \\
\text { Male } \\
\text { Female }\end{array}$ & & $\begin{array}{c}1.00 \text { (reference) } \\
1.02^{* *}(1.01,1.03)\end{array}$ & & $\begin{array}{c}1.00 \text { (reference) } \\
1.01^{*}(1.00,1.03)\end{array}$ \\
\hline $\begin{array}{l}\text { Age of the household head } \\
15-34 \text { years } \\
35-54 \text { years } \\
55 \text { years and above }\end{array}$ & & $\begin{array}{l}1.00 \text { (reference) } \\
1.00(0.99,1.02) \\
1.00(0.99,1.02)\end{array}$ & & $\begin{array}{l}1.00 \text { (reference) } \\
1.01(0.99,1.02) \\
1.01(1.00,1.03)\end{array}$ \\
\hline $\begin{array}{l}\text { Education level of the household head } \\
\text { No education/preschool } \\
\text { Primary } \\
\text { Middle/JSS/JHS } \\
\text { Secondary/SSS/SHS } \\
\text { Postsecondary }\end{array}$ & & $\begin{array}{c}1.00 \text { (reference) } \\
1.03^{* *}(1.01,1.05) \\
1.04^{* *}(1.02,1.06) \\
1.05^{* *}(1.03,1.07) \\
1.07^{* *}(1.05,1.10)\end{array}$ & & $\begin{array}{l}1.00 \text { (reference) } \\
1.02(1.00,1.04) \\
1.02^{*}(1.00,1.04) \\
1.02^{*}(1.00,1.04) \\
1.03^{*}(1.01,1.05)\end{array}$ \\
\hline $\begin{array}{l}\text { Marital status of the household head } \\
\text { Never married nor lived together } \\
\text { Currently married } \\
\text { Formerly/ever married }\end{array}$ & & $\begin{array}{l}1.00 \text { (reference) } \\
0.99(0.97,1.00) \\
0.99(0.98,1.01)\end{array}$ & & $\begin{array}{l}1.00 \text { (reference) } \\
1.00(0.98,1.01) \\
0.99(0.98,1.01)\end{array}$ \\
\hline $\begin{array}{l}\text { Toilet facilities } \\
\text { Unimproved } \\
\text { Improved }\end{array}$ & & & $\begin{array}{l}1.00 \text { (reference) } \\
0.99(0.97,1.01)\end{array}$ & $\begin{array}{l}1.00 \text { (reference) } \\
0.99(0.97,1.01)\end{array}$ \\
\hline $\begin{array}{l}\text { Place of residence } \\
\text { Rural } \\
\text { Urban }\end{array}$ & & & $\begin{array}{c}1.00 \text { (reference) } \\
1.10^{* *}(1.05,1.16)\end{array}$ & $\begin{array}{c}1.00 \text { (reference) } \\
1.10^{* *}(1.04,1.15)\end{array}$ \\
\hline $\begin{array}{l}\text { Household size } \\
7 \text { members and above } \\
4-6 \text { members } \\
1-3 \text { members }\end{array}$ & & & $\begin{array}{l}1.00 \text { (reference) } \\
1.00(0.98,1.02) \\
1.01(0.99,1.03)\end{array}$ & $\begin{array}{l}1.00 \text { (reference) } \\
1.00(0.98,1.02) \\
1.01(0.99,1.03)\end{array}$ \\
\hline $\begin{array}{l}\text { Household wealth index } \\
\text { Poorest } \\
\text { Poor } \\
\text { Middle } \\
\text { Richer } \\
\text { Richest } \\
\text { Intercept (community) }\end{array}$ & $0.88^{* *}(0.86,0.90)$ & $0.85^{* *}(0.82,0.88)$ & $\begin{array}{l}1.00 \text { (reference) } \\
1.06^{* *}(1.02,1.11) \\
1.16^{* *}(1.11,1.22) \\
1.19^{* *}(1.13,1.24) \\
1.19^{* *}(1.14,1.25) \\
0.77^{* *}(0.70,0.79)\end{array}$ & $\begin{array}{l}1.00 \text { (reference) } \\
1.06^{* *}(1.02,1.10) \\
1.16^{* *}(1.10,1.21) \\
1.18^{* *}(1.12,1.23) \\
1.18^{* *}(1.13,1.24) \\
0.73^{* *}(0.68,0.78)\end{array}$ \\
\hline $\begin{array}{l}\text { Random effects } \\
\text { Observations } \\
\text { Second-level units (community) } \\
\text { ICC } \\
\text { QIC } \\
\text { QICu }\end{array}$ & $\begin{array}{c}11829 \\
427 \\
0.88 \\
194101.25 \\
194072.76 \\
\end{array}$ & $\begin{array}{c}11829 \\
427 \\
0.81 \\
195298.46 \\
195277.41\end{array}$ & $\begin{array}{c}11829 \\
427 \\
0.76 \\
195294.11 \\
195240.20\end{array}$ & $\begin{array}{c}11829 \\
427 \\
0.76 \\
195111.03 \\
195065.67\end{array}$ \\
\hline
\end{tabular}

${ }^{* *} p \leq 0.01 ;{ }^{*} p \leq 0.05$; ICC: intracommunity correlation coefficient; QIC: quasi-likelihood information criterion; QICu: the simplified version of the QIC.

requires heavy use of water. Thus, it is plausible that female heads, to reduce the burden that comes with fetching water from far distanced places, will ensure that the households they are heading have good access to water and sanitation facilities. The results that we obtained here are consistent with those of previous studies, which found that femaleheaded households were more likely to have access to improved sources of drinking water and sanitation facilities [9-12, 14, 17].

The household head's education level was statistically significantly associated with the likelihood of having access to an improved source of drinking water and toilet facilities. Households with heads with no formal education had a lower probability of having access to improved sources of drinking water and toilet facilities. Generally, education is a resource factor of quality health outcomes in communities in
sub-Saharan Africa. This is because educated people are usually more aware of conditions that guarantee their wellbeing, and they could have easier access to resources that can create healthy conditions around them. This implies that educated household heads in this study may have utilized their resources to provide their households with improved water and toilet facilities. These results are in consonance with the results of studies with a similar scope [10-13, 17, 19].

In the model for toilet facility access, the age of the household head predicted the likelihood of having access to improved toilet facilities but not access to improved sources of drinking water. Households with heads who were at least 35 years old had a higher chance of having access to improved toilet facilities. This suggests that as people age, they become more conscious of their health and may desire to 
TABLe 7: Predictors of access to improved toilet facilities.

\begin{tabular}{|c|c|c|c|c|}
\hline Explanatory variables & Model 0 aPR (95\% CI) & Model 1 aPR (95\% CI) & Model 2 aPR (95\% CI) & Model 3 aPR (95\% CI) \\
\hline $\begin{array}{l}\text { Sex of the household head } \\
\text { Male } \\
\text { Female }\end{array}$ & & $\begin{array}{c}1.00 \text { (reference) } \\
1.20^{* *}(1.06,1.25)\end{array}$ & & $\begin{array}{c}1.00 \text { (reference) } \\
1.18^{* *}(1.05,1.33)\end{array}$ \\
\hline $\begin{array}{l}\text { Age of the household head } \\
15-34 \text { years } \\
35-54 \text { years } \\
55 \text { years and above }\end{array}$ & & $\begin{array}{c}1.00 \text { (reference) } \\
1.88^{* *}(1.60,2.21) \\
2.62^{* *}(2.21,3.11) \\
\end{array}$ & & $\begin{array}{c}1.00 \text { (reference) } \\
1.70^{* *}(1.45,2.00) \\
2.60^{* *}(2.18,3.10)\end{array}$ \\
\hline $\begin{array}{l}\text { Education level of the household head } \\
\text { No education/preschool } \\
\text { Primary } \\
\text { Middle/JSS/JHS } \\
\text { Secondary/SSS/SHS } \\
\text { Postsecondary }\end{array}$ & & $\begin{array}{c}1.00 \text { (reference) } \\
1.14(0.96,1.35) \\
1.47^{* *}(1.26,1.70) \\
2.16^{* *}(1.79,2.59) \\
3.77^{* *}(3.18,4.48)\end{array}$ & & $\begin{array}{c}1.00 \text { (reference) } \\
1.12(0.93,1.36) \\
1.19^{*}(1.01,1.41) \\
1.45^{* *}(1.20,1.75) \\
2.12^{* *}(1.74,2.58)\end{array}$ \\
\hline $\begin{array}{l}\text { Marital status of the household head } \\
\text { Never married nor lived together } \\
\text { Currently married } \\
\text { Formerly/ever married }\end{array}$ & & $\begin{array}{c}1.00 \text { (reference) } \\
1.61^{* *}(1.32,1.96) \\
1.12(0.89,1.41) \\
\end{array}$ & & $\begin{array}{c}1.00 \text { (reference) } \\
1.31^{* *}(1.09,1.56) \\
1.07(0.87,1.33)\end{array}$ \\
\hline $\begin{array}{l}\text { Sources of drinking water } \\
\text { Unimproved } \\
\text { Improved }\end{array}$ & & & $\begin{array}{l}1.00 \text { (reference) } \\
0.82(0.62,1.09)\end{array}$ & $\begin{array}{l}1.00 \text { (reference) } \\
0.82(0.62,1.07)\end{array}$ \\
\hline $\begin{array}{l}\text { Place of residence } \\
\text { Rural } \\
\text { Urban }\end{array}$ & & & $\begin{array}{c}1.00 \text { (reference) } \\
0.62^{* *}(0.50,0.77)\end{array}$ & $\begin{array}{c}1.00 \text { (reference) } \\
0.63^{* *}(0.52,0.77)\end{array}$ \\
\hline $\begin{array}{l}\text { Household size } \\
7 \text { members and above } \\
4-6 \text { members } \\
1-3 \text { members }\end{array}$ & & & $\begin{array}{c}1.00 \text { (reference) } \\
0.77^{* *}(0.65,0.85) \\
0.48^{* *}(0.42,0.55)\end{array}$ & $\begin{array}{c}1.00 \text { (reference) } \\
0.80^{* *}(0.70,0.92) \\
0.59^{* *}(0.51,0.69)\end{array}$ \\
\hline $\begin{array}{l}\text { Household wealth index } \\
\text { Poorest } \\
\text { Poor } \\
\text { Middle } \\
\text { Richer } \\
\text { Richest } \\
\text { Intercept (community) }\end{array}$ & $0.12^{* *}(0.11,0.14)$ & $0.03^{* *}(0.02,0.04)$ & $\begin{array}{c}1.00 \text { (reference) } \\
1.21(0.92,1.59) \\
1.81^{* *}(1.37,2.34) \\
3.19^{* *}(2.40,4.25) \\
9.44^{* *}(7.08,12.61) \\
0.10^{* *}(0.07,0.16) \\
\end{array}$ & $\begin{array}{c}1.00 \text { (reference) } \\
1.19(0.90,1.54) \\
1.77^{* *}(1.33,2.34) \\
2.90^{* *}(2.14,3.93) \\
7.33^{* *}(5.37,10.00) \\
0.03^{* *}(0.02,0.06) \\
\end{array}$ \\
\hline $\begin{array}{l}\text { Random effects } \\
\text { Observations } \\
\text { Second-level units (community) } \\
\text { ICC } \\
\text { QIC } \\
\text { QICu }\end{array}$ & $\begin{array}{c}11829 \\
427 \\
0.35 \\
10235.76 \\
10226.42\end{array}$ & $\begin{array}{c}11829 \\
427 \\
0.31 \\
10086.30 \\
10077.33\end{array}$ & $\begin{array}{c}11829 \\
427 \\
0.26 \\
9511.01 \\
9460.96\end{array}$ & $\begin{array}{c}11829 \\
427 \\
0.25 \\
9615.39 \\
9600.36\end{array}$ \\
\hline
\end{tabular}

${ }^{* *} p \leq 0.01$; ${ }^{*} p \leq 0.05$; ICC: intracommunity correlation coefficient; QIC: quasi-likelihood information criterion; QICu: the simplified version of the QIC.

utilize facilities that improve their quality of life. Although undocumented in the literature, it is suggestive to argue that old age in most African communities is associated with respect and civility. Therefore, individuals of at least 35 years may be morally compelled to provide improved sanitation facilities in order to avoid the public ridicule that is often associated with open defecation. Also, anecdotal evidence suggests that citizens within this age group are more likely to have some form of income source or employment which likely makes them able to afford utilities. While this finding from our study confirms earlier findings that the age of the household head is a predictor of the household's access to an improved source of drinking water [11], it contradicts findings from other investigations that found no associations between these variables [10].
In Model 3 of access to improved toilet facilities, households with heads who were currently married at the time of the survey had a higher probability of having access to improved toilet facilities, but this had no effect on their access to improved sources of drinking water. The protective effect of the household head being married against the lack of access to improved toilet facilities is consistent with the findings of other studies [15]. However, the study's results are in contrast with those of other studies with regard to household heads who were not currently married. One study, using the 2008 Ghana Demographic and Health Survey, found that households with heads who had never married were more likely to have had access to improved toilet facilities [17]. Also, while the study found no predictive effect of the marital status of household heads on the 
likelihood of having access to improved sources of drinking water, it was observed in other studies [12, 17]. The implication is that contextual differences exist regarding access to sanitation resources and the factors influencing such access.

Urban households were more likely to have access to improved sources of drinking water, but rural households were more likely to have access to improved toilet facilities. These results are in consonance with the results of other researchers who found that urban households were more likely to have access to improved sources of drinking water $[9,11-14,17,19]$. In this study and those of others $[9,14]$, an increase in the probability of access to improved toilet facilities was observed for rural households contrary to the expectation. This brings an interesting twist to popular discourses about the nature of unequal access to utilities between urban and rural settings as the view has often been that urban dwellers have better access [33]. The protective effect of rural household's access to an improved type of toilet facility could be attributed to the positive contributions of both local and international NGO activities in rural communities on sanitation [34]. However, with regard to access to toilet facilities, some studies found urban households to have had a higher chance of access $[13,17]$.

Households with more members were more likely to have access to improved toilet facilities but not access to improved drinking water. Other studies also found that larger households were more likely to have access to improved toilet facilities [17]. This finding could mean that the larger the households, the more the resources they may have for building improved toilet facilities. Unlike this study's results, other studies indicated that household size predicted the likelihood of having access to improved sources of drinking water $[12,17]$.

Nonpoorest households had a greater probability of having access to both improved sources of drinking water and improved toilet facilities. Similar to the findings of this study, other studies found that household wealth is a major factor in explaining the differences in the probability of having access to improved sources of drinking water and toilet facilities [9-14, 16, 17, 19]. The convergence of findings from different contexts on this subject strongly suggests that poverty is a major risk factor that prevents many households from accessing improved water and sanitation facilities.

\section{Limitations and Strengths}

This study used data from a cross-sectional survey; therefore, the results from analyzing the data cannot establish causal relationships. The conclusions in this study are restricted to associations between the explanatory and the criterion variables. Besides the limitation, there is one strength of the study. The study used the GDHS dataset that is nationally representative and large. Therefore, findings from the analyses can be generalized for the entire Ghanaian population. The GDHS programs have consistently been undertaken about 7 times already since the 1980s; thus, their sampling methodologies, data collection procedures, and questionnaires have been improved.

\section{Conclusions}

This study sought to investigate the predictive factors of the household's access to improved sources of drinking water and improved toilet facilities in Ghana. About $88 \%$ of households had access to improved sources of drinking water and $12 \%$ to improved toilet facilities. The effects of household head and household socioeconomic factors on access to improved sources of drinking water and toilet facilities vary from one community of residence to another. The following households had a higher probability of access to improved sources of drinking water: households with female heads, households with heads who have at least middleschool-level education, urban residence households, and households that were nonpoorest. With regard to improved toilet facilities, female-headed households had a higher chance of access, as well as those whose heads had at least middle-school-level education, were at least 35 years old, or were currently married. Also, rural households, those with a minimum of seven members, and those with at least middle wealth status had a higher chance of access to improved toilet facilities.

Household wealth was an extremely significant factor in determining access to improved sources of drinking water and toilet facilities. Thus, the authors recommend that the government of Ghana and her development partners should promote policies and programs that enhance citizens' wealth creation capacities. The authors recommend that investments in improving access to water and sanitation facilities in Ghana should be complemented with programs that encourage citizens to obtain a formal education. It is common knowledge that increasing the actual quantity of functional facilities available in a community could greatly influence the households' access. The authors, therefore, recommend that state authorities and nongovernmental organizations pursue policies and intervention that aim at increasing the units of improved toilet facilities and drinking water sources in all communities, taking into account the variations in access attributed to the context of the community where the households were located.

\section{Data Availability}

The 2014 Ghana DHS dataset supporting the analysis of this study is available in the DHS repository. The DHS datasets are available for free after a simple registration process. The minimal dataset used to support the findings of this study is included within the supplementary information file.

\section{Conflicts of Interest}

The authors declare no conflicts of interest.

\section{Acknowledgments}

The authors are sincerely grateful to the DHS Program for granting access to its datasets for analyses in this paper. 


\section{Supplementary Materials}

"MultiLevelData.xlsx" is the minimal dataset supporting the findings of the study. (Supplementary Materials)

\section{References}

[1] United Nations, United Nations Resolution on Human Right to Water and Sanitation, U. N. G. Assembly, Ed., United Nations, New York, NY, USA, 2010.

[2] WHO, Ottawa Charter for Health Promotion, World Health Organization, Geneva, Switzerland, 1986.

[3] R. Bain, R. Cronk, J. Wright, H. Yang, T. Slaymaker, and J. Bartram, "Fecal contamination of drinking-water in lowand middle-income countries: a systematic review and metaanalysis," PLoS Medicine, vol. 11, no. 5, article e1001644, 2014.

[4] J. Bartram and S. Cairncross, "Hygiene, sanitation, and water: forgotten foundations of health," PLoS Medicine, vol. 7, no. 11, article e1000367, 2010.

[5] A. Prüss-Ustün, J. Bartram, T. Clasen et al., "Burden of disease from inadequate water, sanitation and hygiene in low-and middle-income settings: a retrospective analysis of data from 145 countries," Tropical Medicine \& International Health, vol. 19, no. 8, pp. 894-905, 2014.

[6] A. A. Patunru, "Access to safe drinking water and sanitation in Indonesia," Asia \& the Pacific Policy Studies, vol. 2, no. 2, pp. 234-244, 2015.

[7] M. H. Forouzanfar, A. Afshin, L. T. Alexander et al., "Global, regional, and national comparative risk assessment of 79 behavioural, environmental and occupational, and metabolic risks or clusters of risks, 1990-2015: a systematic analysis for the Global Burden of Disease Study 2015," The Lancet, vol. 388, no. 10053, pp. 1659-1724, 2016.

[8] Ghana Statistical Service (GSS) and Macro International Inc. (MI), Ghana Demographic and Health Survey 2014, GSS and MI, Calverton, MA, USA, 2015.

[9] J. N. Mulenga, B. B. Bwalya, and K. Kaliba-Chishimba, "Determinants and inequalities in access to improved water sources and sanitation among the Zambian households," International Journal of Development and Sustainability, vol. 6, no. 8, pp. 746-762, 2017.

[10] I. R. Abubakar, "Access to sanitation facilities among Nigerian households: determinants and sustainability implications," Sustainability, vol. 9, no. 4, p. 547, 2017.

[11] B. R. Dil, B. Behera, and A. Ali, "Household access to water and choice of treatment methods: empirical evidence from Bhutan," Water Resources and Rural Development, vol. 5, pp. 1-16, 2015.

[12] S. Irianti, P. Prasetyoputra, and T. P. Sasimartoyo, "Determinants of household drinking-water source in Indonesia: an analysis of the 2007 Indonesian family life survey," Cogent Medicine, vol. 3, no. 1, article 1151143, 2016.

[13] P. Prasetyoputra and S. Irianti, "Access to improved sanitation facilities in Indonesia: an econometric analysis of geographical and socioeconomic disparities," Journal of Applied Sciences in Environmental Sanitation, vol. 8, no. 3, pp. 215224, 2013.

[14] D. R. Sarmento, An Analysis of Access to Improved Drinking Water and Sanitation and Distance to the Water Source in a Newly Independent Country, Timor-Leste: Assessing Geographical and Socioeconomic Disparities, ScholarWorks@ Georgia State University, Atlanta, Georgia, 2015.

[15] E. C. Koskei, R. C. Koskei, M. C. Koske, and H. K. Koech, "Effect of socio-economic factors on access to improved water sources and basic sanitation in bomet municipality, Kenya," Research Journal of Environmental and Earth Sciences, vol. 5, no. 12, pp. 714-719, 2013.

[16] W. Awoke and S. Muche, "A cross sectional study: latrine coverage and associated factors among rural communities in the District of Bahir Dar Zuria, Ethiopia," BMC Public Health, vol. 13, no. 1, pp. 1-6, 2013.

[17] E. A. Adams, G. O. Boateng, and J. A. Amoyaw, "Socioeconomic and demographic predictors of potable water and sanitation access in Ghana," Social Indicators Research, vol. 126, no. 2, pp. 673-687, 2016.

[18] D. Boateng, M. Tia-Adjei, and E. A. Adams, "Determinants of household water quality in the Tamale Metropolis, Ghana," Journal of Environment and Earth Science, vol. 3, no. 7, pp. 70-77, 2013.

[19] A. M. Mahama, K. A. Anaman, and I. Osei-Akoto, "Factors influencing householders' access to improved water in lowincome urban areas of Accra, Ghana," Journal of Water and Health, vol. 12, no. 2, pp. 318-331, 2014.

[20] L. M. Dickinson and A. Basu, "Multilevel modeling and practice-based research," Annals of Family Medicine, vol. 3, no. 1, pp. S52-S60, 2005.

[21] A. J. Barros and V. N. Hirakata, "Alternatives for logistic regression in cross-sectional studies: an empirical comparison of models that directly estimate the prevalence ratio," $B M C$ Medical Research Methodology, vol. 3, no. 1, p. 21, 2003.

[22] A. Espelt, M. Marí-Dell'Olmo, E. Penelo, and M. BosqueProus, "Estimación de la Razón de Prevalencia con distintos modelos de Regresión: ejemplo de un estudio internacional en investigación de las adicciones," Adicciones, vol. 29, no. 2, pp. 105-112, 2016.

[23] C. A. S. Santos, R. L. Fiaccone, N. F. Oliveira et al., "Estimating adjusted prevalence ratio in clustered cross-sectional epidemiological data," BMC Medical Research Methodology, vol. 8, no. 1, p. 80, 2008.

[24] G. Zou and A. Donner, "Extension of the modified Poisson regression model to prospective studies with correlated binary data," Statistical Methods in Medical Research, vol. 22, no. 6, pp. 661-670, 2013.

[25] C. Edgar, H. Sarah, and M. Andy, The Ghana Poverty and Inequality Report:Using the 6th Ghana Living Standards Survey, UNICEF, New York, NY, USA, 2016.

[26] WHO/UNICEF, Progress on Sanitation and Drinking Water: 2015 Update and MDG Assessment, World Health Organization, New York, NY, USA, 2015.

[27] O.-W. A. Nana Yaw and F. Sarah, Access to Clean Drinking Water \& Sustainable Water Management in Ghana, Delegation of German Industry and Commerce in Ghana, Accra, Ghana, 2018.

[28] R Core Team, R: A Language and Environment for Statistical Computing, R Foundation for Statistical Computing, Vienna, Austria, 2019, https://www.R-project.org/.

[29] SAS Institute, Inc., SAS/STAT Software, Version 9.4, SAS Institute, Inc., Cary, NC, USA, 2018.

[30] W. Pan, "Akaike's information criterion in generalized estimating equations," Biometrics, vol. 57, no. 1, pp. 120-125, 2001.

[31] M. Szklo and J. Nieto, Epidemiology: Beyond the Basics, Jones \& Bartlett Learning, Burlington, MA, USA, 2012.

[32] J. F. Hair Jr., W. C. Black, B. J. Babin, R. E. Anderson, and R. L. Tatham, Multivariate Data Analysis, Macmillan, New York, NY, USA, 3 edition, 1995. 
[33] M. Ofori-Mensah, Access to Basic Public Services: Challenges Ghana Must Overcome, The Institute of Economic Affairs, Accra, Ghana, 2017.

[34] M. M. Dangah, "The role of NGOs in the provision of water and sanitation in Northern Ghana: the case of pronet in the Nadowli district geography and rural development," MPhil thesis, Kwame Nkrumah University of Science and Technology, Kumasi, Ghana, 2012. 




The Scientific World Journal
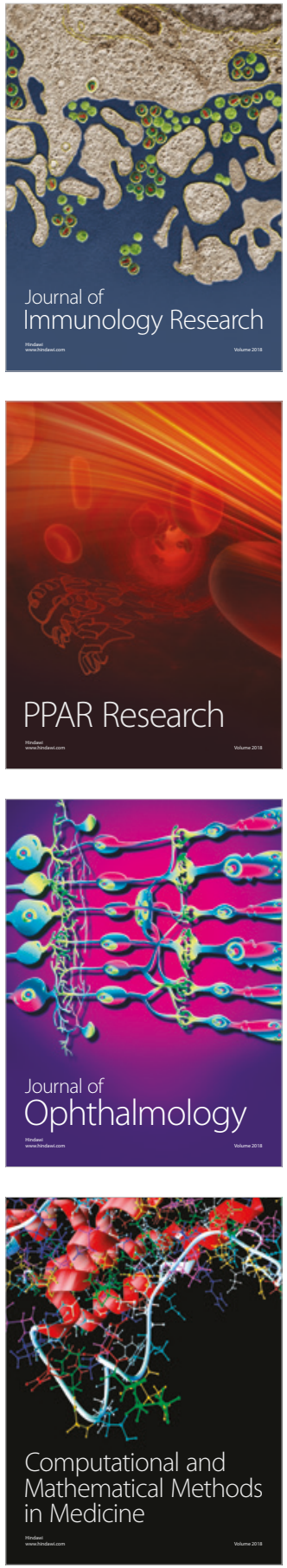

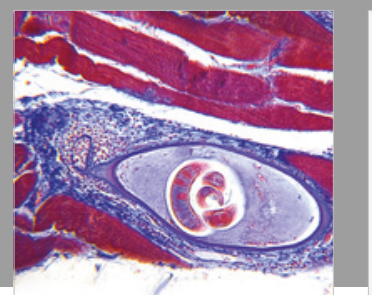

Gastroenterology Research and Practice

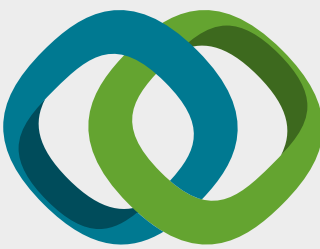

\section{Hindawi}

Submit your manuscripts at

www.hindawi.com
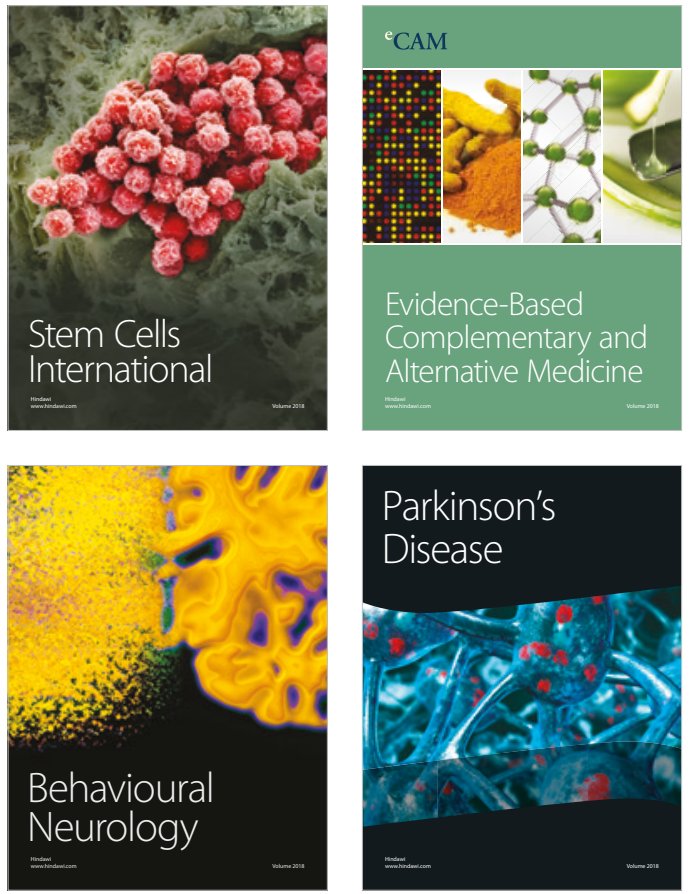



ournal of

Diabetes Research

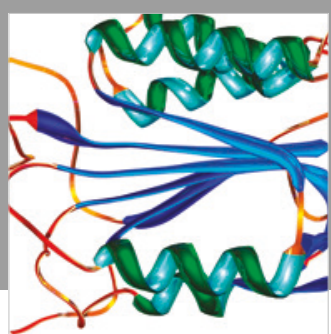

Disease Markers
